\title{
A COMPARISON OF TIME MANAGEMENT SKILLS AMONG ACCOUNTING, BUSINESS, AND INFORMATION SYSTEMS STUDENTS BY AGE AND GENDER
}

\author{
Jason W. Powell, Northwestern State University, powellja@nsula.edu \\ Lily J. Pharris, Northwestern State University, pharrisl@nsula.edu \\ Marcia M. Hardy, Northwestern State University, hardym@nsula.edu
}

\begin{abstract}
Higher education is a self-regulating environment where students practice time management skills to increase academic success. Students differ on these practices, and understanding these differences is an important step in helping students improve their skills. The purpose of this study is to compare the similarities and differences of time management beliefs of students enrolled in higher education programs now and three decades ago. To accomplish this aim, methodologies from earlier studies were replicated, with minor changes to reflect changes in student behaviors over the past few decades. From there, significant differences between current and previous results were identified to determine if time management beliefs and practices have changed over time. This study uses a selfreporting survey to explore the differences among students majoring in accounting, business, and information systems programs. Researchers investigate detailed results in two factors of time-management, daily planning and confidence in long-term planning, by comparing women $(N=170)$ and men $(N=150)$, and three ages groups: academically young $(N=160)$, borderline mature $(N=68)$, and mature students $(N=92)$. The analysis suggests that significant differences exist between women and men in daily planning and between young and mature students.
\end{abstract}

Keywords: Time Management, Business Students, Self-Regulation, Academic Success Skills

\section{INTRODUCTION}

Time management is a skill that college students need for success in higher education. It is essential because students must manage tasks involving complex information processing in a self-regulated environment. Proper time use can benefit the student by increasing productivity and decreasing stress, while bringing life into balance as they manage schoolwork, extracurricular activities, family, and employment. Students understand that time is a limited resource, which provides motivation for them to evaluate their time habits and develop intentional plans to maximize its use.

Time management skills and practices differ among individuals, but developing and applying them requires awareness, judgment, monitoring, and alertness. One can assume that students are motivated self-evaluators and aware of their practices; thus, researchers can use self-reporting techniques to understand the role these skills play in academic environments. There have been studies using this technique, including Britton and Tesser (1991), Alay and Kocak (2002), and García-Ros et al. (2004). One study of interest is Trueman and Hartley (1996) where differences involving gender and age among students majoring in psychology are explored using a Likert-scale survey to cover two factors: daily planning and confidence in long-term planning.

The present study extends the body of literature by investigating the time management practices and skills of accounting, business, and information systems majors. The purpose of this study is to compare time management beliefs and practices between students enrolled in higher education programs now and studies by Britton and Tesser (1991) and Trueman and Hartley (1996) from nearly thirty years ago. Specifically, this study focuses on differences between age groups and genders. The Britton and Tesser (1991) Likert-scale survey has been adapted to resemble the Trueman and Hartley (1996) survey instrument to capture self-reported skills and practices. In addition to reporting overall daily planning and confidence in long-term planning scores like Trueman and Hartley, the current research also delves into the 14 individual questions to further understand the differences. The analysis involves 320 students and shows empirical evidence that overall significant differences in skills and practices exist (1) between men and women and (2) among age groups of students majoring in business fields. 
This investigation seeks to contribute knowledge to the current research gap related to differences among female and male college students, and age-related disparities found in time management practices among business majors. Recognizing that men and women approach planning differently and exhibit shared aims in long-term planning lends value to the creation of classroom projects and study experiences that honor these differences. Discerning that younger students may employ long term planning skills differently than an older student population contributes to a better understanding that age may impact profitable and unprofitable time management routines among these groups in the university setting. While this study seeks to provide further research into the perceptions of time management practices among business students in the field of higher education, it is also an important work advancing current knowledge and providing valuable insights into the roles of gender and age related to total time management skills.

\section{LITERATURE REVIEW}

Trueman and Hartley (1996) initiated a predominant comparative research inquiry on time-management skills related to age and gender. The investigation focused on the time-management skills of mature and traditional entry-level university psychology students. It provides a significant understanding into differences related to gender across two predominant factors: (1) daily planning and (2) confidence in long term planning. The 293 student subjects were divided into three groups: 18-20 year old students identified as the "traditional entry students," 21-25 year old students identified as the "borderline mature students", and students aged 26 and above identified as the "older mature students". Following the results analysis, the authors conclude that the older mature students reported notably more enhanced time management skills than the borderline mature and traditional entry students. Additionally, the authors' analysis concluded that female students conveyed significantly better time-management skills than male students.

Burke and Collins (2001) conducted research into the differences between genders in leadership styles and management skills specifically related to the study of accountants' management styles and effectiveness. A cited skill required in management is the ability to use time efficiently. Survey data for this study was based on responses from 2,800 members of the American Woman's Society of Certified Public Accountants (AWSCPA) and matched against the 2,800 male members of the American Institute of Certified Public Accountants (AICPA). They analyzed seven management skills including "personal organization and time management" described as, "working efficiently, making good use of time. Organizing your work tasks, setting priorities, and expediting the paperwork process." This section accounted for eight items in the survey, with an example being "make good use of your time." The assessment of perceived time management effectiveness discovered that there are gender differences in three management skills, including time management. They report females to have a higher perceived effectiveness than their male counterparts. Collins and Killough (1992) note that perceived efficiency in female time management may be due to the work/family balance they rely on to handle the daily routine. Females may learn to adapt and make more efficient use of their time to succeed by being more accustomed to managing interruptions in their daily tasks.

An additional cross-sectional study by Kaya, Kaya, Pallos and Kucuk (2012), using a time management inventory, assessed the time-management skills of 584 university nursing and midwifery students in terms of gender, age, and anxiety levels. The data results concluded that gender is a factor in time management efficiency. Female students' average scores were higher than the male students and they were more successful in managing their time, did not waste their time, and were incorporating all the tasks within a shorter expected period than the male students. There was no significant difference between genders involving time planning. This study reported the age groups of students did not affect average time management scores. While Truman and Hartley (1996) found students above the age of 25 managed their time better than those below 21, and between 21-23, a contradictory account by Başak et al. (2008) reported a different result indicating the traditional entry-level student in the age range of 20 and below were more successful in time management skills than student who were 21 and above.

Kaushar's study (2013) on the impact of time management on academic performance of college students as reported in the Journal of Business and Management findings indicates an important and positive relationship between time planning, time management and academic performance among students. Naik, et. al (2019) conducted a crosssectional study with 243 undergraduate medical students from a tertiary health-care teaching institution utilizing a time management questionnaire with 18 items in a 5-point Likert scale. The study identified that more than two-thirds 
of the students had poor to average time management skills whereas students possessing the skill of 'high readiness for self-direction' scored significantly higher on the questionnaire.

In 2014, Khatib reported on a relationship between time management, students' stress, gender, and university academic achievement. The study stratified the 352 participants by gender with a mean age of 23 years and ages ranging from 18 to 39 years. The findings presented female students as reporting higher time management as compared to male counterparts. A higher time management and a perceived lower level of stress was associated with higher levels of academic achievement and the most significant predictor of higher academic achievement was related to time management. They identified that successful time management self-regulation is a significant impact factor as students deal with the challenge of adequately allocating their resources among a variety of academic and personal activities.

Oettingen, et al. (2015) implemented a mental contrasting with implementation intentions (MCII) intervention skills program with 51 American undergraduate students ranging in age from 18 to 21 years of age with the aim of improving student time management. Although they did not report gender and age, the results indicate that following the intervention, compared to the control group, there was a reported significant improvement in more effective time management. This study suggests self-regulatory strategies can help students to remedy time management issues.

\section{METHODOLOGY AND HYPOTHESES}

The survey instrument, Table 1, uses a 14-question Likert scale time management scale adapted from Britton and Tesser (1991) that is almost identical to the Trueman and Hartley (1996) study. Participants respond by selecting one from 'never', 'infrequently', 'sometimes', 'frequently', 'always', which are coded with a score of 1 to 5 . A higher scorer indicates a positive time management skill or practice, a lower score indicates a negative skill or practice; thus, for questions $1-7,10,12$, and 14 , the option 'always' receives 5 ; for questions $8,9,11$, and 13 , the scale is reversed so 'always' receives a 1. The scores are summed for the two factors of Daily Planning (ranging from 5-25), Confidence in Long Term Planning (ranging from 9-45), and the Total Time Management (ranging from 14-70).

Table 1. Time-Management Questionnaire

\section{Daily Planning}

1. Do you make a list of the things you have to do each day?

2. Do you plan your day before you start it?

3. Do you make a schedule of the activities you have to do on work/school days?

4. Do you write a set of goals for yourself for each day?

5. Do you spend time each day planning?

Confidence in Long-Term Planning

6. Do you have a clear idea of what you want to accomplish during the next week?

7. Do you set and honor priorities?

8. Do you often find yourself doing things which interfere with your schoolwork simply because you hate to say "No" to people? ${ }^{\mathrm{a}}$

9. Do you believe that there is room for improvement in the way you manage your time? ${ }^{\text {a }}$

10. Do you make constructive use of your time?

11. Do you continue unprofitable routines or activities? a

12. Do you have a set of goals for the entire semester?

13. The night before a major assignment is due, are you usually still working on it? ${ }^{a}$

14. Do you regularly review your class notes, even when a test is not imminent?

${ }^{a}$ Reversed scored so that 'never' received a score of 5

\section{Hypotheses}

The general hypothesis is that a significant difference exists in time management practices between men and women and among various age groups. The selected age groups for this study mimic Trueman and Hartley (1996) by categorizing respondents into young (18-20 years), borderline mature (21-25), and mature (25 or older) students. 
Two hypotheses were identified:

H1: There is a significant difference between men and women in (a) daily planning, (b) confidence in long-term planning, and (c) overall time management practice.

H2: There is a significant difference among age groups in (a) daily planning, (b) confidence in long-term planning, and (c) overall time management practice.

\section{Participants}

The survey involved students majoring in accounting, business, and information systems programs at a four-year public institution in Louisiana for three semesters: fall 2017, spring 2018, and fall 2018. Participants voluntarily completed the survey in a freshmen-level introduction to information technology course or a senior-level capstone course. The institutional research office of the investigated university provided demographic information using the student's identification number. A total of 320 students participated, which includes 150 men, 170 women, 160 young, 68 borderline, and 92 mature students. All participants were 18 years or older. Table 2 provides the sex and age distribution for each category.

Table 2. Sample Sex and Age Distribution

\begin{tabular}{|l|l|c|c|c|}
\hline & & $\begin{array}{c}\text { Young } \\
(\mathbf{2 0})\end{array}$ & $\begin{array}{c}\text { Borderline } \\
(\mathbf{2 1} \text { - 25) }\end{array}$ & $\begin{array}{c}\text { Mature } \\
(\mathbf{2 ~ 2 6})\end{array}$ \\
\hline \multirow{4}{*}{ Men } & Mean & 18.4 & 22.6 & 36.0 \\
\cline { 2 - 5 } & s.d. & 0.6 & 1.5 & 7.2 \\
\cline { 2 - 5 } & $\mathrm{N}$ & 97 & 20 & 33 \\
\hline \multirow{4}{*}{ Women } & Mean & 18.3 & 21.9 & 35.2 \\
\cline { 2 - 5 } & s.d. & 0.6 & 1.2 & 7.8 \\
\cline { 2 - 5 } & $\mathrm{N}$ & 63 & 48 & 59 \\
\hline \multirow{3}{*}{ otal } & Mean & 18.3 & 22.1 & 35.5 \\
\cline { 2 - 5 } & s.d. & 0.6 & 1.3 & 7.5 \\
\cline { 2 - 5 } & $\mathrm{N}$ & 160 & 68 & 92 \\
\hline
\end{tabular}

\section{RESULTS}

This study used the R Project for Statistical Computing for reliability testing. The coefficients using the Cronbach alpha reliability test are in Table 3 for the age groups, decomposed into the daily planning and confidence in longterm planning factors, and the overall time management. The results indicate that the survey instrument is internally reliable for the respondents.

Table 3. Cronbach Alpha Reliability for Time Management Scales

\begin{tabular}{|l|c|c|c|c|c|}
\hline & $\begin{array}{c}\text { Young } \\
(\mathbf{2 0 )}\end{array}$ & $\begin{array}{c}\text { Borderline } \\
(\mathbf{2 1} \mathbf{- 2 5})\end{array}$ & $\begin{array}{c}\text { Mature } \\
(\mathbf{2 ~ 2 6})\end{array}$ & $\begin{array}{c}\text { All Mature } \\
(\mathbf{>} \text { 21) }\end{array}$ & $\begin{array}{c}\text { Total } \\
\text { Sample }\end{array}$ \\
\hline Daily Planning & 0.82 & 0.81 & 0.88 & 0.86 & 0.85 \\
\hline Confidence in Long-Term Planning & 0.64 & 0.68 & 0.76 & 0.72 & 0.68 \\
\hline Overall Time Management & 0.77 & 0.79 & 0.86 & 0.84 & 0.80 \\
\hline
\end{tabular}

Following the statistical model presented in Britton and Tesser (1991) and Trueman and Hartley (1996), the R Project for Statistical Computing was used for hypothesis testing with t-Tests between sexes and one-way ANOVA among age groups, assuming equal variance as reported by the Bartlett's Test for Homogeneity of Variances. Table 4 summarizes the mean scores for daily planning, confidence in long-term planning, and total time management, decomposed by sex and age group. Women scored higher than men in all categories except with borderline students 
on confidence in long-term planning. Borderline and mature students scored higher than young students in every category except women who are borderline mature students. Table 5 and Table 6 shows the mean responses of each question, the totals, and the t-Test and ANOVA p-values from comparing between the sexes and among the age groups. Overall, the mean responses were positive (above 3.0) for all questions except 'daily goal setter', 'room for improvement', and 'procrastination'. The mean total score for daily planning was 16.41, 29.52 for confidence in longterm planning, and total time management total was 45.93 .

Table 4. Mean Scores on Time Management Scales

\begin{tabular}{|l|l|r|r|r|r|}
\hline & & $\begin{array}{c}\text { Young } \\
(\mathbf{2 0})\end{array}$ & $\begin{array}{c}\text { Borderline } \\
(\mathbf{2 1} \text { - 25) }\end{array}$ & $\begin{array}{c}\text { Mature } \\
(\mathbf{2 6})\end{array}$ & $\begin{array}{l}\text { Total } \\
\text { Sample }\end{array}$ \\
\hline \multirow{3}{*}{$\begin{array}{l}\text { Daily } \\
\text { Planning }\end{array}$} & Men & 14.5 & 17.2 & 16.9 & 15.4 \\
\cline { 2 - 6 } & Women & 16.1 & 17.7 & 18.3 & 17.3 \\
\cline { 2 - 6 } & Total & 15.1 & 17.5 & 17.8 & 16.4 \\
\hline $\begin{array}{l}\text { Confidence in } \\
\text { Long-Term } \\
\text { Planning }\end{array}$ & Men & 28.9 & 29.4 & 29.2 & 29.0 \\
\cline { 2 - 6 } & Women & 29.5 & 29.1 & 30.7 & 29.8 \\
\cline { 2 - 6 } & Total & 29.1 & 29.2 & 30.2 & 29.4 \\
\hline \multirow{2}{*}{$\begin{array}{l}\text { Motal Time } \\
\text { Management }\end{array}$} & Men & 43.4 & 46.6 & 46.2 & 44.4 \\
\cline { 2 - 6 } & Women & 45.6 & 46.8 & 49.1 & 47.1 \\
\cline { 2 - 6 } & Total & 44.2 & 46.7 & 48.0 & 45.8 \\
\hline
\end{tabular}

Table 5. Mean Responses and t-Test Results Comparing Women and Men

\begin{tabular}{|c|c|c|c|c|c|}
\hline Question & $\begin{array}{c}\text { All } \\
(\mathrm{N}=320)\end{array}$ & $\begin{array}{l}\text { Women } \\
(\mathrm{N}=170)\end{array}$ & $\begin{array}{c}\text { Men } \\
(\mathrm{N}=150)\end{array}$ & $\mathbf{t}$ & $\mathbf{P}$ \\
\hline \multicolumn{6}{|l|}{ Daily Planning } \\
\hline 1. List making & 3.24 & 3.52 & 2.93 & 4.766 & $0.000 * * *$ \\
\hline 2. Pre-day planner & 3.64 & 3.81 & 3.45 & 3.093 & $0.002 * *$ \\
\hline 3. Activity scheduling & 3.67 & 3.89 & 3.41 & 3.800 & $0.000^{* * *}$ \\
\hline 4. Daily goal setter & 2.63 & 2.66 & 2.60 & 0.457 & 0.648 \\
\hline 5. Daily planner & 3.23 & 3.43 & 2.99 & 3.480 & $0.000 * * *$ \\
\hline Mean Total & 16.41 & 17.32 & 15.39 & 3.918 & $0.000 * * *$ \\
\hline \multicolumn{6}{|c|}{ Confidence in Long-Term Planning } \\
\hline 6. Weekly planning & 3.76 & 3.88 & 3.63 & 2.145 & 0.033* \\
\hline 7. Priority setter & 3.94 & 4.02 & 3.85 & 1.620 & 0.106 \\
\hline 8. Unable to say "no" a & 3.43 & 3.37 & 3.49 & -1.118 & 0.265 \\
\hline 9. Room for improvement ${ }^{\mathrm{a}}$ & 1.88 & 1.84 & 1.93 & -0.810 & 0.419 \\
\hline 10. Constructive use of time & 3.68 & 3.72 & 3.63 & 1.170 & 0.243 \\
\hline 11. Unprofitable routines ${ }^{a}$ & 3.28 & 3.30 & 3.26 & 0.402 & 0.688 \\
\hline 12. Semester goal setter & 3.69 & 3.75 & 3.63 & 0.940 & 0.348 \\
\hline 13. Procrastination ${ }^{\mathrm{a}}$ & 2.76 & 2.76 & 2.76 & -0.012 & 0.991 \\
\hline 14. Regular note taker & 3.10 & 3.26 & 2.91 & 3.245 & $0.001^{* *}$ \\
\hline Mean Total & 29.52 & 29.79 & 29.02 & 1.611 & 0.108 \\
\hline Time Management Total & 45.93 & 47.11 & 44.41 & 3.230 & $0.001^{* *}$ \\
\hline
\end{tabular}

Significance codes: $0^{\text {‘***’ }}, 0.001^{\text { ‘**', }}, 0.01^{\text {‘*’ }}, 0.05$ '?' 


\section{Issues in Information Systems}

Volume 21, Issue 3, pp. 1-10, 2020

\section{Daily Planning}

Women reported significantly higher scores than men for each question in daily planning, except for daily goal setting. A summary of the t-Test results is in Table 7. Women did score higher in daily goal setting, but it was not significant. This led to a significant difference in the total daily planning score as women $(\mathrm{M}=17.32$, s.d. $=4.39)$ scored higher than men $(M=15.39$, s.d. $=4.45) ; t(318)=3.918, p=0.000$. There was also significant difference among the age groups with every question as borderline and mature students reported higher scores than young students; these differences are in Table 8. The Tukey HSD post hoc analysis, Table 9, shows that the significant differences occur between young and borderline students and between young and mature students. Borderline and mature students provided similar answers, having no significant differences.

Table 6. Mean Responses and ANOVA Results Comparing Age Groups

\begin{tabular}{|c|c|c|c|c|c|c|}
\hline Question & $\begin{array}{c}\text { All } \\
(\mathrm{N}=320)\end{array}$ & $\begin{array}{c}\text { Young } \\
(\mathrm{N}=160)\end{array}$ & $\begin{array}{c}\text { Borderline } \\
(\mathbf{N}=68)\end{array}$ & $\begin{array}{c}\text { Mature } \\
(\mathrm{N}=92)\end{array}$ & $\mathbf{F}$ & $\mathbf{p}$ \\
\hline \multicolumn{7}{|l|}{ Daily Planning } \\
\hline 1. List making & 3.24 & 3.00 & 3.49 & 3.49 & 7.460 & $0.000^{* * *}$ \\
\hline 2. Pre-day planner & 3.64 & 3.46 & 3.71 & 3.91 & 5.799 & $0.003^{* *}$ \\
\hline 3. Activity scheduling & 3.67 & 3.41 & 3.97 & 3.89 & 8.816 & $0.000 * * *$ \\
\hline 4. Daily goal setter & 2.63 & 2.39 & 2.79 & 2.93 & 6.388 & $0.002 * *$ \\
\hline 5. Daily planner & 3.23 & 2.87 & 3.59 & 3.58 & 17.340 & $0.000 * * *$ \\
\hline Mean Total & 16.41 & 15.13 & 17.54 & 17.80 & 14.180 & $0.000^{* * *}$ \\
\hline \multicolumn{7}{|c|}{ Confidence in Long-Term Planning } \\
\hline 6. Weekly planning & 3.76 & 3.54 & 3.87 & 4.08 & 8.198 & $0.000 * * *$ \\
\hline 7. Priority setter & 3.94 & 3.87 & 4.09 & 3.95 & 1.313 & 0.270 \\
\hline 8. Unable to say "no" a & 3.43 & 3.58 & 3.18 & 3.36 & 4.331 & $0.014^{*}$ \\
\hline 9. Room for improvement ${ }^{\mathrm{a}}$ & 1.88 & 1.83 & 1.79 & 2.05 & 1.853 & 0.158 \\
\hline 10. Constructive use of time & 3.68 & 3.64 & 3.65 & 3.76 & 0.989 & 0.373 \\
\hline 11. Unprofitable routines ${ }^{a}$ & 3.28 & 3.31 & 2.94 & 3.48 & 7.749 & $0.000 * * *$ \\
\hline 12. Semester goal setter & 3.69 & 3.59 & 3.71 & 3.87 & 1.644 & 0.195 \\
\hline 13. Procrastination ${ }^{a}$ & 2.76 & 2.78 & 2.72 & 2.75 & 0.119 & 0.888 \\
\hline 14. Regular note taker & 3.10 & 2.98 & 3.22 & 3.23 & 2.593 & 0.076 . \\
\hline Mean Total & 29.52 & 29.10 & 29.16 & 30.52 & 3.134 & $0.045^{*}$ \\
\hline Time Management Total & 45.93 & 44.23 & 46.71 & 48.33 & 9.031 & $0.000 * * *$ \\
\hline
\end{tabular}

Significance codes: 0 ‘***’, 0.001 ‘**’, 0.01 ‘*’, 0.05 ‘.'

Table 7. Significant Differences in Daily Planning Between Women and Men

\begin{tabular}{|l|c|c|c|c|c|c|}
\hline & \multicolumn{2}{|c|}{ Women } & \multicolumn{2}{c|}{ Men } & \multicolumn{2}{c|}{ t-test } \\
\hline Question & M & s.d. & M & s.d. & t & p \\
\hline List making & 3.52 & 1.08 & 2.93 & 1.15 & 4.766 & 0.000 \\
\hline Pre-day planner & 3.81 & 0.97 & 3.45 & 1.09 & 3.093 & 0.002 \\
\hline Activity scheduling & 3.89 & 1.10 & 3.41 & 1.13 & 3.800 & 0.000 \\
\hline Daily planner & 3.43 & 1.10 & 2.99 & 1.13 & 3.480 & 0.001 \\
\hline Daily Planning Score & 17.32 & 4.39 & 15.39 & 4.45 & 3.918 & 0.000 \\
\hline
\end{tabular}


Table 8. Significant Differences in Daily Planning Among Age Groups

\begin{tabular}{|l|c|c|c|c|c|c|c|c|}
\hline & \multicolumn{2}{|c|}{ Young } & \multicolumn{1}{c|}{ Borderline } & \multicolumn{2}{c|}{ Mature } & \multicolumn{2}{c|}{ ANOVA } \\
\hline Question & M & s.d. & M & s.d. & M & s.d. & F & p \\
\hline List Making & 3.00 & 1.08 & 3.49 & 1.10 & 3.49 & 1.23 & 7.460 & 0.001 \\
\hline Pre-day planner & 3.46 & 1.09 & 3.71 & 1.04 & 3.91 & 0.89 & 5.799 & 0.003 \\
\hline Activity Scheduling & 3.41 & 1.17 & 3.97 & 1.01 & 3.89 & 1.08 & 8.816 & 0.000 \\
\hline Daily goal setter & 2.39 & 1.23 & 2.79 & 1.20 & 2.93 & 1.24 & 6.388 & 0.002 \\
\hline Daily planner & 2.87 & 1.11 & 3.59 & 1.04 & 3.58 & 1.06 & 17.340 & 0.000 \\
\hline Daily Planning Score & 22.54 & 5.41 & 25.5 & 4.91 & 25.83 & 5.50 & 14.180 & 0.000 \\
\hline
\end{tabular}

Table 9. Post Hoc Significant Differences in Daily Planning Among Age Groups

\begin{tabular}{|l|l|l|r|}
\hline Question & $\begin{array}{c}\text { Young - } \\
\text { Borderline }\end{array}$ & $\begin{array}{c}\text { Young - } \\
\text { Mature }\end{array}$ & $\begin{array}{c}\text { Borderline - } \\
\text { Mature }\end{array}$ \\
\hline List Making & $0.009^{* *}$ & $0.003^{* *}$ & 1.000 \\
\hline Pre-day planner & 0.230 & $0.003^{* *}$ & 0.417 \\
\hline Activity Scheduling & $0.001^{* *}$ & $0.003^{* *}$ & 0.896 \\
\hline Daily goal setter & 0.065. & $0.002^{* *}$ & 0.754 \\
\hline Daily planner & $0.000^{* * *}$ & $0.000^{* * *}$ & 0.997 \\
\hline Daily Planning Score & $0.000^{* * *}$ & $0.000^{* * *}$ & 0.923 \\
\hline
\end{tabular}

\section{Confidence in Long-Term Planning}

There were two questions that resulted in significant differences between women and men in confidence in long-term planning. In weekly planning, women $(M=3.88$, s.d.=1.05) have significantly higher scores than men $(M=3.63$, s.d.=1.08); $\mathrm{t}(318)=2.145, \mathrm{p}=0.033$. Women $(\mathrm{M}=3.26$, s.d.=1.02) also had higher scores in regular note taking than men $(\mathrm{M}=2.91$, s.d. $=0.92) ; \mathrm{t}(318)=3.245, \mathrm{p}=0.001$. These differences were not enough to generate a significant difference in the confidence in long-term planning score. The age groups did have significant differences for four of the nine questions. The confidence in long-term planning score was also significantly difference with young students $(M=29.10$, s.d. $=4.49)$ having similar scores with borderline students $(M=29.16$, s.d.=4.71) but significantly lower scores than mature students $(\mathrm{M}=30.52$, s.d. $=4.51) ; \mathrm{F}(2,317)=3.134, \mathrm{p}=0.05$. The Tukey HSD post hoc analysis, Table 9 , shows that the significant differences are mostly between young and borderline students, and between young and mature students. Borderline and mature students where only significantly different in continuing unprofitable routines.

Table 10. Post Hoc Significant Differences in Confidence in Long-Term Planning Among Age Groups

\begin{tabular}{|l|c|c|c|}
\hline Question & $\begin{array}{c}\text { Young - } \\
\text { Borderline }\end{array}$ & $\begin{array}{c}\text { Young - } \\
\text { Mature }\end{array}$ & $\begin{array}{c}\text { Borderline - } \\
\text { Mature }\end{array}$ \\
\hline Weekly planning & 0.076 & $0.000^{* * *}$ & 0.426 \\
\hline Unable to say "no" & $0.014^{*}$ & 0.207 & 0.471 \\
\hline Unprofitable routines & $0.009^{* *}$ & 0.309 & $0.000^{* * *}$ \\
\hline Regular note taker & 0.197 & $0.121^{\mathrm{a}}$ & 0.999 \\
\hline Confidence in Long-Term Planning & 0.995 & $0.045^{*}$ & 0.148 \\
\hline
\end{tabular}

Significance codes: 0 ‘***’ $0.001^{\text {‘**’ }} 0.01^{\text {‘*’ }} 0.05$ ‘’

${ }^{a}$ Fisher-LSD test confirms significant difference despite the Tukey HSD test

\section{Time Management Total}

Women $(M=47.11$, s.d. $=7.85)$ scored significantly higher than men $(M=44.11$, s.d. $=7.37)$ in total time management; $\mathrm{t}(318)=3.230, \mathrm{p}=0.001$. The age groups also showed significant difference; $\mathrm{F}(2,317)=9.031, \mathrm{p}=0.000$. Young students 
( $M=44.23$, s.d.=7.36) score lower than borderline students ( $M=46.71$, s.d.=7.36), and borderline students scored lower than mature students $(M=48.33$, s.d. $=8.01)$. The Tukey HSD post hoc analysis, Table 11, shows that the significant different is between young and borderline students, and between young and mature students; however, there was no significant difference between borderline and mature students.

Table 11. Post Hoc Significant Differences in Total Time Management Among Age Groups

\begin{tabular}{|c|c|c|c|c|}
\hline \multirow[b]{2}{*}{ Major } & \multirow{2}{*}{$\begin{array}{c}\text { Mean } \\
\text { Difference }\end{array}$} & \multicolumn{2}{|c|}{ 95\% Confidence Interval } & \multirow[b]{2}{*}{$\mathbf{p}$} \\
\hline & & Lower Bound & Upper Bound & \\
\hline Young - Borderline & 2.4746 & -0.1007 & 5.0499 & 0.063 \\
\hline Young - Mature & 4.0948 & 1.7672 & 6.4225 & 0.000 \\
\hline Borderline - Mature & 1.6020 & -1.2248 & 4.4652 & 0.374 \\
\hline
\end{tabular}

DISCUSSION

\section{Daily Planning}

Daily planning questions focused on time-management skills for daily activities. A higher score implies that the student routinely plans and organizes their day. Women responded with higher scores than men in all five questions, with four being significantly higher. This also led to women having significantly higher daily planning scores. With respect to age groups, younger students scored significantly lower on four of the five questions when compared to borderline students, and lower on all five questions compared to mature students. Borderline and mature students show similar responses. This resembles some of the results in the Trueman and Hartley (1996) study. Unfortunately, the former study does not provide the results on individual questions, but they do confirm a significant difference with women scoring higher than men involving the daily planning score. Concerning age groups, the results between the two studies differ. Trueman and Hartley (1996) findings showed that borderline students had lower daily scores than younger and mature students, and that younger and mature students were similar. Therefore, researchers fail to reject hypothesis H1(a) because there is significant difference between women and men in daily planning, and researchers fail to reject hypothesis H2(a) because there are significant differences between young and more mature students.

\section{Confidence in Long-Term Planning}

Long-term planning questions focused on determining the student's confidence in planning activities beyond the current day. A higher score implies that the student is thinking of longer-term planning and organization of activities. Women scored higher in seven of the nine questions; however, only two questions produced a significantly higher score, and the confidence in long-term planning score is similar for both. The age groups show a significant difference in four of the nine questions, as well as the overall score. Individual questions show a mix among the groups, but in general, the significant differences are between young students and the two other groups while borderline and mature students are similar. The findings in the current study resemble some of the results in the Trueman and Hartley (1996) study. As with daily planning, they did not provide results for individual questions, but they found no significant difference between women and men with confidence in long-term planning. As seen in the earlier research, the results indicated that mature students generated higher scores; however, they found their young and borderline students were similar. Therefore, researchers fail to accept hypothesis H1(b) because there is little evidence to support a significant difference between women and men, and researchers fail to reject hypothesis H2(b) because there were significant differences between young students and more mature students.

\section{Total Time-Management}

The total time-management score is the aggregate average sum of the question responses, with higher scores implying the student has greater use of time-management skills. Women scored significantly higher than men overall. Younger students scored significantly lower than the other two groups, but borderline and mature students had similar scores. This partly resembles the 1996 study by Trueman and Hartley. Researchers also found a significant difference with women scoring higher, and there was a significant difference among the age group; however, the significant difference was between young and mature students while young and borderline students have similar scores. Therefore, researchers fail to reject hypothesis H1(c) and H2(c) because there is evidence of significant differences between women and men, and among the age groups. 


\section{Limitations}

In general, the results resemble the Trueman and Hartley (1996) study. Still, it is important to discuss an unexplained difference between the findings of the studies. Specifically, Trueman and Hartley found greater similarities between the younger and borderline age groups than in this present research. One limitation that may explain this is that the average age of the young student in the current student is 18.3 years-old as compared to 19.0 years-old in the Trueman and Hartley investigation. Younger students in the previous study were closer, on average, to the borderline group than in the current study. The approximate 8-month difference may be an important time when young students gain better time management practices. In addition, students in the previous study were psychology majors, while students in the current study were accounting, business, and information systems majors, which may have general differences among them.

Furthermore, the current study relies on students to self-report time management practices in a survey provided during a course. Even though the survey asked participants to answer questions honestly, a student's desire to look positive may introduce bias in his or her answers. The survey also used convenience sampling to select participants from one business school; thus, it is difficult to make a generalization about larger populations. In addition, the univariate statistical model using t-Tests and ANOVA, replicated in this study based on Britton and Tesser (1991) and Trueman and Hartley (1996), is limited. Future research could incorporate multivariate models such as MANOVA and covariance, multiple discriminate analysis, and principle components analysis, while exploring additional data dimensions. Finally, the survey instrument is based on Britton's and Tesser's (1991) questionnaire but limited to similar questions used by Trueman and Hartley (1996). As with Trueman and Hartley's study, these questions are general when more educationally specific questions may help understand differences among school of business majors.

\section{CONCLUDING REMARKS}

The current study is important because it allows educators to compare similarities and differences between the time management beliefs held by students now and a study from nearly thirty years ago. The findings are relevant for educators of information systems, accounting, and business majors to recognize that time management beliefs of students have remained somewhat constant over the past three decades because (1) many students still lack these necessary time management skills and practices and (2) research already exists to help educators develop time management skills in students. It is expected that numerous interventions that have proven effective in building time management skills in students over the last few decades remain relevant in the classroom today.

The findings also suggest that many of the differences in time management beliefs between genders and ages have persisted over the three decades. While these findings may suggest that gender roles may play an important part in time management beliefs and practices, the results also offer support for higher education programs to invest in the development of time management skills early in the curriculum so incoming students can be better prepared to meet the demands of college coursework and be more successful in their chosen major.

Finally, given that time management training enhances student performance in courses (Willman et al., 2016) and reduces perceived stress (Häfner, Stock, \& Oberst, 2015), educators working in programs with a higher ratio of male students, such as computer information systems or computer sciences, may greatly benefit from the findings of this study. By offering students extra time management training and support early in the program through orientation activities or initial coursework, these programs have an opportunity to help the students that already exhibit a greater tendency for deficient time management skills. Offering time management training at the earliest stages of academic coursework for the students lacking these skills could result in improved student performance and success in their chosen academic programs.

\section{REFERENCES}

Alay, S., \& Kocak, S. (2002) Validity and reliability of time management questionnaire. Hacettepe University, Review of Faculty of Education, 22, 9-13. 
Başak, T., Uzun, Ş., \& Arslan, F. (2008). Hemşirelik yüksek okulu öğrencilerinin zaman yönetimi becerileri. TAF Preventive Medicine Bulletin, 7(5), 429-434.

Britton, B. K., \& Tesser, A. (1991). Effects of time-management practices on college grades. Journal of educational psychology, 83(3), 405.

Burke, S., \& Collins, K. M. (2001). Gender differences in leadership styles and management skills. Women in management review; 16, 5/6; ProQuest Research Library pg. 244-256.

Collins, K. M., \& Killough, L. N. (1992). An empirical examination of stress in public accounting. Accounting, Organizations and Society, 17(6), 535-547.

García-Ros, R., Pérez-González, F., \& Hinojosa, E. (2004). Assessing time management skills as an important aspect of student learning: The construction and evaluation of a time management scale with Spanish high school students. School Psychology International, 25(2), 167-183.

Häfner, A., Stock, A., \& Oberst, V. (2015). Decreasing students’ stress through time management training: an intervention study. European journal of psychology of education, 30(1), 81-94.

Kaya, H., Kaya, N., Palloş, A. Ö., \& Küçük, L. (2012). Assessing time-management skills in terms of age, gender, and anxiety levels: A study on nursing and midwifery students in Turkey. Nurse Education in Practice, 12(5), 284-288. Retrieved from https://www.sciencedirect.com/science/article/pii/S1471595312001126

Khatib, A. S. (2014). Time management and its relation to students' stress, gender and academic achievement among sample of students at $\mathrm{Al}$ Ain University of science and technology, UAE. International Journal of Business and Social Research (IJBSR), 4(5), 47-58.

Kaushar, M. (2013). Study of impact of time management on academic performance of college students. Journal of Business and Management, 9(6), 59-60.

Naik, B. N., Rangasamy, S., \& Vrushabhendra, H. N. (2019). Time management among undergraduate medical students: A study from a tertiary health-care teaching institution in Puducherry. Journal of Integrated Health Sciences, 7(2), 39.

Oettingen, G., Kappes, H. B., Guttenberg, K. B., \& Gollwitzer, P. M. (2015). Self-regulation of time management: Mental contrasting with implementation intentions. European Journal of Social Psychology, 45(2), 218229.

Trueman, M., \& Hartley, J. (1996). A comparison between the time-management skills and academic performance of mature and traditional-entry university students. Higher education, 32(2), 199-215.

Willman, S., Lindén, R., Kaila, E., Rajala, T., Laakso, M. J., \& Salakoski, T. (2015). On study habits on an introductory course on programming. Computer Science Education, 25(3), 276-291 